\title{
The Inter-Subjectivity as the Enlargement of the Self in Others: Richard Rorty's Critique of the Self-Creation in the Community of Language
}

\section{Do Kien Trung1 and Bui Van Mua ${ }^{2 *}$ \\ ${ }^{1}$ Graduate School of Humanities, Kobe University, Japan \\ 2University of Economics Ho Chi Minh City, Vietnam}

*Corresponding author: Bui Van Mua, Faculty of Political Studies, University of Economics Ho Chi Minh City, Vietnam, Email: bvmua@ueh.edu.vn

\section{Research article \\ Volume 2 Issue 1}

Received Date: December 15, 2018

Published Date: January 18, 2019

DOI: $10.23880 /$ phij-16000112

\section{Abstract}

People, as cognitive entities, do not have experience if there is not language that takes the role of mediates matchmaking and brings them experience. It also means that the use of language plays a decisive role in the human experience's meaning and in the decision in real life. Based on Wittgenstein's standpoint of the role of language, Rorty mentions that the symbols of life on transcendental matters such as religion or non-historical rational foundation - which are formed by the consciousness on the transcendent or the foundation - must be proved to be meaningless and categorized as matters of general political-cultural context, in other words, within the realm of the intersubjectivity in the community of language. He also agrees with Robert Brandom that there are no other principles if they do not belong to social standards. Social standards are the principles which are used in conversations and communications between people. The meanings, which have been made rather than found, are the meanings that given only in social discussions. When an individual describes the characteristics of an object, these characteristics are just provided by his consciousness on that object. Others cannot verify this private experience. However, that person can describe his feelings about that object to others by using the same language system in the same context. The individual experiences become the notion of the object when the intersubjectivity is established in conversation. That means the intersubjectivity creates the objectivity. Determining the existence of the self and the relationship between it and the external environment plays a vital role in shaping a thinking style of the relationship between individuals and communities, not only in the enactment of political policies but also in the interpretation of personal behavior psychologically. In this article, I will analyze one of the most controversial concepts in Richard Rorty's views on the self-creation, the inter-subjectivity. My article has two parts: firstly, the explanation of the self-awareness of an individual on others; secondly, the standards in perception are relative and the relativity in perceiving values can be seen as a new form of nihilism.

Keywords: Richard Rorty; Intersubjectivity; Contingency of language; Community of language 


\section{Philosophy International Journal}

\section{Introduction}

The concept of the objectivity is only an expression form of the inter-subjectivity that has received mixed arguments. However, even in the field of science, this view not only receives negative comments, but also agrees. In the realm of sciences, which based on "a real love of truth" to "know how things really were" that reminded Charles Pierce by Susan Haack, ${ }^{1}$ scientists always need principle platforms to build their new ideas and experiments to create knowledge of reality. Those principle platforms are not the foundation of truth that needs to be proved. They are new vocabularies that are created by scientists when the old vocabularies cannot be used to describe the new steps in socio-historical progress effectively; Rorty mentions that in Galilean science and the Enlightenment. Alan Haworth referred the similarity between Rorty and Dworkin in the ideas that "science as the activity of inventing descriptions of the world for purposes of predicting and controlling what happens" and "the search for explanations which work" 2 . Obviously, there are arguments that there is no consciousness that can exist outside a particular context and historical conditions; therefore, the new vocabulary is no more than irrational which should be considered as an opposite side with rational - the current vocabulary and fundamental premises - as the cause of every philosophical argument. Rorty agrees with Donald Davidson that if we use the concept rational not as an "absolute criteria" but an "internal coherence", so we can keep moving forward for the notion of irrational is something like "a form of selfcriticism and reform which we hold in high esteem"3. Form this standpoint, there is a maximum expansion in all dimensions of thinking and knowledge, with the abandonment of any fundamental and authoritative metaphysics. It is a Rorty's suggestion that there is no unchanging truth or a cognitive expectation of unchanging truth that promotes an open dialogue in cognition progress, which Stefano Petrucciani ${ }^{4}$ agrees with Rorty that it is a post-philosophy that instead of the anger, rebuttal and critics of the justifications, we will justify the critiques.

${ }^{1}$ Susan Haack (2006), p.676.

${ }^{2}$ Alan Haworth (1998), p.106.

${ }^{3}$ Richard Rorty (1989), p.49.

4Petrucciani, Stefano (2007), La Pragmatica di un Liberale Ironico, Il Manisfesto 12 Giugno

\section{The Inter-Subjectivity is what the "I-Self" Sees Itself in Others}

Despite the widely acknowledged fact that Rorty was influenced by Dewey's idea of the denial of the "privileged foundations", Mysak notes that Rorty's account of culture and social practices was a kind of contemporary version of James' in which Rorty tried to replace a theory of knowledge with an expression of social hope. In so doing, he recalled James' viewpoint regarding "what is better for us to believe rather than as the accurate representation of reality" (Rorty, 1979, p. 10). The problem of traditional philosophy is the failed attempt to provide the foundation for the correctness of the knowledge that we, the knowing subject, can use to evaluate the correctness of a social action, or the truthfulness of intellectual activity; in other words, a standard system of value for social practices. Consequently, philosophers are required to admit a proper and non-historical norm that they have access to in order to obtain an indisputable reference system when identifying an object. These epistemological efforts play a highly significant role in forming a platform for cognitive processes for use in assessing whether a particular action or a social project is better or worse than an alternative.

There are many criticisms in Rorty's denial of the foundation of knowledge in cognitive progress towards denying the role of proper knowledge in determining the characteristics of a specific behavior. However, if we establish the framework that the seeking of the foundations of knowledge is not a purpose of cognitive progress, if we consider that the mission of our thinking is the process of improving and finding our "Self" instead of simply aiming at perfecting the thinking process itself, and if we realize that the process of recognizing our "Self" is not merely a self-activity but is in fact based on an organic interaction with others in a community of language, we can determine that the finding of the foundations of knowledge is a progression in thinking that is useful for human solidarity, and that along with the finding of the "Self", we have the ability to improve the socio-historical situation in which we are engaging in language interaction through dialogue. This is a form of "meliorism" (Misak, 2013, p. 228) based on a belief that our society can be improved by human efforts to participate in social practices rather than a purely intellectual capacity-improving process.

Although Rorty is admittedly too radical relative to his pragmatist predecessors, such as James and Dewey, when he advocates replacing "experience" with "discourse", as in Sellars' account of the debunking of the theory of knowledge, we must accept that Peirce should be treated 


\section{Philosophy International Journal}

in the right way, as he provided the idea of an answer that we must recognize in order to arrive at solidarity among the differences. The point is what Peirce expressed, like an answer without proof that we should suppose as motivation and a goal of thought. Rorty, on the other hand, emphasizes that if this kind of answer or goal does not have useful meaning for social practices or provide a better re-description for justification, we should abandon all illusions of an a priori answer.

Why does this point matter? Mysak stresses that Rorty took a step further than all of his pragmatist predecessors with his idea of solidarity as the only thing that matters for us, the knowing subjects (the "inquirers" in Mysak's usage), instead of truth. Richard David Precht points out that the ambition to discover the truth or the purpose of the world is merely a category of human thinking. Innovations in neuroscience and human brain research have proven that human beings and human thinking are not the ultimate goal of evolution. Based on the research of Santiago Ramon y Cajal and William Calvin ${ }^{5}$, Precht contends that the process of nature does not have any inherent meaning: the categories of meaning, purpose, and truth are only valid in the self-awareness process of the cognitive subject at a particular stage of development. In other words, the meaning of the world is only valid to the "I". Then, the "I" is at the center of cognitive activity. The existence of the "I" is a prerequisite for the implementation of cognitive activity, i.e., the existence of the "I" is presumed to be a reality. It is because that the subject must be identified before we can discuss the seeking of truth. However, the "I" is a vile entity that has been rejected by neuroscience. Therefore, the "I" is merely something that is inferred, as pointed out by David Hume. The question is, from what is the "I" inferred? We cannot answer this question by stating e.g. that the "I" is inferred from the emotions of "I" or the idea of "I". To deal with this vicious circle, philosophers usually use the word "self" rather than "I". The self is some sort of center of our will and arguments that has been formed in the process of receiving material from reality, and can be used to express our account of cognitive objects. Hence, the self divides itself into two categories: I-self (as the selfconcept) and Me-self (as the sense of self-value).

William James contends that the I-self acts while the Me-self comments, and that the sense of self-value is a purely subjective credit provided to the I-self by the Meself6. My Me-self comes from other Me-selfs which are outside of my I-self. This inquiry leads us to two

${ }^{5}$ Richard David Precht (2011), p. 18-26.

6Ibid., p. 34-42. conclusions: first, all value systems and the sense of value systems are only meaningful in the context of the interchange among the I-selfs; second, the sense of selfvalue possessed by the I-self is provided by the Me-self, but the I-self does not have access to all information from the external world, meaning that it is necessary to posit a standard for selective acceptance of the I-self. In other words, the I-self can find and understand the world when the I-self comprehends that the image of the world is reflected in the thinking of the I-self, because all things that the knowing subject knows about the world cannot be available as innate images. The only innate thing is the cognitive ability to obtain personal experiences. This is the issue that brain researchers such as Paul MacLean or Marie Jean Pierre Flourens ${ }^{7}$ did not explain.

Nerve impulses and links between brain cells are prerequisites for the creation of the characteristics of the Self, such as emotion, vibration, hope, desire, etc. However, the deciphering of the brain's central and functional components cannot be applied to explain the production of spirit, consciousness, and the things that make up the identity of the Self. The external environment affects the mind in which filtered through the senses that evoke different sensory experiences on each individual.

The private experiences of one person are only perceived in the personal domain. Given this, how can an "I-self" (a person) understand the "Me-selfs" of others? If private experiences can only be felt in the personal domain, how can a single person understand the Me-self's providing? Tran Duc Thao explains this by using the reflection of the Self's image in other persons. In the earliest forms of language, which used single syllables, a person would voice the syllable and point to the object he was referring to. The action of pointing in combination with the single syllable is performed as a gesture of communication with other members of the community. At the time, the speaker had to assume that the listeners understood what he meant, meaning that the listeners were a reflection image of himself outside of himself. If not, the listeners would not be able to understand the implications of that action. Meanwhile, subjectivity is no longer an activity of self-awareness, but has become the perception of subjectivity itself in others, i.e. intersubjectivity.

This communication process, or the transformation of subjectivity into inter-subjectivity, can function if and only if the speaker and listeners have a similar background through which to communicate. Linguistic

7Ibid., p.34-42. 


\section{Philosophy International Journal}

similarity (in the use of grammatical structures and vocabulary) is a compulsory premise. The similarities in living habits and hunting practices in the prehistoric period also formed a background for this kind of communication. However, when we talk to each other using more complex forms, as in exchanges and debates over value systems, this background must be extended to include such elements as culture, politics, religion, knowledge, etc., along with expressions of the Self in communication, e.g. emotions, understanding, empathy, etc. Conversations around complex subjects require certain criteria to conclude. Propositions offered in the course of communication must have a fulcrum if a judgement is to be asserted or negated. Expanding to the scope of community and society, not just personal experience, we must admit that without these fulcrums, or "standards", the process of communicating and exchanging value systems is merely a presentation of content or an idea.

\section{How can we understand this kind of standard?}

A standard is a system of opinions, reasons and/or beliefs that serve as a benchmark for an argument or a tendency. To be a standard, firstly, these reasons must be a true statement, i.e., they must correspond to the conventions of grammar and vocabulary and must also express the accuracy of the object to which that statement is referring. For instance, "Killing innocent people is evil behavior", "Children must be filial to their parents", "The right to life, freedom and the pursuit of happiness are the inviolable right of man". These statements are true because they are proven to be true in social practices, rather than via pure inferences in thought. Secondly, if these statements cannot be substantiated by reality, they must promote an engine of truth. This is the key to distinguishing between Rorty and his predecessors. Charles Peirce and his followers, such as Misak, believe that the inquirers need to set goals for our practices of assertion and inquiry, which they call "belief" and which are "stable and independent" (Misak, 2013, p. 232) from individual and community opinions. This kind of belief is not an illusory dream of a supernatural or metaphysical truth; rather, it is a goal set for social practices in order to help the inquirers create solidarity and provide a method to evaluate experience. For his part, Rorty puts himself in a completely different position. He is very consistent in his view of "dialogues" and ignores everything outside dialogue. From his standpoint, what a community thinks right is truth. Truth is the best thing a community believes. That is, when asserting that something is truth, a community recognizes the correctness of a particular standard and demonstrates their consistency with it. Rorty denies this tendency. Misak repeats his core idea that "the gap between justification and truth is the gap between the actual good and the possible better" 8 because what a community believes may not be "true" in the sense that belief does not provide any better idea regarding how to make things right. A better path for "the knowing subject" is to extend our community's references beyond the limitations of our community; that is, in this extended relationship, a community plays the role of a subjectivity, and this extension leads to a larger inter-subjectivity between the standards. A community is an intersubjectivity between subjectivities. We can call this expansion an inter-inter-subjectivity.

The truth of statements and the promotion of an engine for making things better are not enough to form a standard. To be a standard, a consensus of most participants in a specific conversation must be established as the most important factor of the solidarity. This is because, when subjectivity transforms into intersubjectivity in the first step and continue to expand towards inter-inter-subjectivity, the content of a standard cannot be saved as the way it was when that standard was first established and validated in the community. The extension of subjectivity to inter-inter-subjectivity is inversely proportional to the specificity of a standard; that is, the content of the standard will need to become simpler, more abstract and more universal. To the extent that a standard is more universal, it is more likely to be consensual than local, community-based constraints. However, this solidarity and universality are neither immutable nor an eternal value system. The movement and transformation of social practices will inevitably change the content of consensus regarding this universality.

\section{Relativity Instead of Stability}

Despite many criticisms levelled at his controversial statements, the President of the United States Donald Trump brought a message of resonance and consensus to other countries on November 10, 2017 in Da Nang, Vietnam. President Trump delivered a keynote speech in the $29^{\text {th }}$ Asia-Pacific Economic Cooperation forum. In that speech, President Trump launched a strategy of linking the India-Pacific countries ("Indo-Pacific region") as a counterweight to China's "Belt and Road Initiative" by emphasizing the independence and distinct values of each country:

With your help, this entire region has emerged and it is still emerging as a beautiful constellation of nations,

${ }^{8}$ See Cheryl Misak (2013), p. 235. 


\section{Philosophy International Journal}

each its own bright star, satellites to none and each one, a people, a culture, a way of life, and a home.

Those of you who have lived through these transformations understand better than anyone the value of what you have achieved. You also understand that your home is your legacy, and you must always protect it.

In the process of your economic development, you've sought commerce and trade with other nations, and forged partnerships based on mutual respect and directed toward mutual gain ${ }^{9}$.

The speech received applause from the majority of APEC members, not only because it praised the progress of each country, but also because it made reference to anti-globalization and the fight against economic aggression through multilateral trade agreements, where the interests of small countries are vulnerable. It should be added that on September 19, 2017, in an address to the United Nations held two months before the APEC forum, President Trump also emphasized respect for the cultural, traditional and political differences of other countries:

We do not expect diverse countries to share the same cultures, traditions, or even systems of government. But we do expect all nations to uphold these two core sovereign duties: to respect the interests of their own people and the rights of every other sovereign nation ${ }^{10}$.

Here, consensus is elevated into a standard for solidarity, in that President Trump introduced three mandatory standards for a sustainable economic alliance: "fairness", "respect" and "reciprocity"11. These standards have enjoyed consensus in the socio-political context in the first half of the $21^{\text {st }}$ century, especially after the Sept. 11 attacks in the United States and the massacre at the Charlie Hebdo newspaper in France, both times at which the clash between economics, politics, and cultural or religious differences was pushed to extremes and gave rise to conflict. These concepts are emphasized as a guideline for the conduct of nations, and also advocated for by the right-wing and nationalist movements from the "small nations", which had previously been in a

9 https://www.whitehouse.gov/the-press-office/2017/11/10/remarkspresident-trump-apec-ceo-summit-da-nang-vietnam

10 https://www.whitehouse.gov/the-pressoffice/2017/09/19/remarks-president-trump-72nd-session-unitednations-general-assembly

${ }^{11}$ https://www.whitehouse.gov/the-press-office/2017/11/10/remarkspresident-trump-apec-ceo-summit-da-nang-vietnam dependent position and have now developed into the "newly industrialized countries" through their remarkable achievements.

The three standards listed above, namely fairness, respect and reciprocity, certainly could not have been introduced in the $19^{\text {th }}$ century, when European and American empires sent warships to invade Asian and African countries, or after the end of World War II, when the universal political, cultural and economic standards were divided into the two opposite poles of communist and capitalist ideology. For instance, in 1945, Vietnamese President Ho Chi Minh sent several diplomatic notes through the Office of Strategic Services (OSS), the forerunner of the CIA, to then-US President Harry S. Truman regarding the United States' proposal to recognize and protect the independence of Vietnam. At that time, however, the colonial and influential divisions established after the Yalta Conference made it very clear among the larger nations that the Indochinese peninsula was under the influence and interests of France, and the United States of America needed a close ally at the United Nations Security Council. Obviously, in such a context, adherence to standards such as respect, fairness, etc. is impossible and unconvincing.

From this point, Rorty seems to agree with Pierce that the inquirers can find something like a common sense that "goes beyond mere unforced agreement" to "something we can aspire to"12. However, this common sense or these standards cannot be interpreted or inferred from outside the specific context in which the discourses are produced. All criteria for a consensus must be discussed in conversation, and the right or wrong of an argument must be decided within the sphere of conversation, not from metaphysics or an external reference system. Rorty points out that the line between justification and truth is very clear: justification is used for the seeking of the solidarity between differences in conversation here and now, while truth is a goal for "future justifiability"13. However, this kind of "future" is not a form of transcendence over all that is true and false that forms the foundation of our beliefs. Rorty emphasizes that truth is ultimately only a justification in another conversation, when the participants return to the same topic, but in a different context. Here, what was supposed to be true in the first dialogue may be rejected and proven false in the second one.

${ }^{12}$ Cheryl Misak (2013), p. 230.

13Ibid., p.236. 
This means that when an inquirer assumes that one or more propositions are true based on evidence and factual data now, and those propositions, along with the consensus of the community, synthesize into the belief of the "knowing subjects", he or she must also admit the possibility that existing facts and evidence in the future will prove those propositions false in another context. This key point led to a debate between Peircean pragmatists (including Misak) and Rorty that revolves around the position and role of truth. However, my mention of the word "key" is also the solution to unravelling this contradiction. To return to Misak's core idea, it should be noted that her arguments in The American Pragmatists regarding proving the validity of a proposition are only valid for a certain period (of time) with valid facts. The flow of space-time is cut off by linguistic conventions among the participants in a conversation. At this point, her position resembles that of the later Wittgenstein. However, it is in the "relative" nature of the justification that she recognizes the need to return to Peirce with a belief in truth.

Misak thinks that we need more than just standards in argument. This is because the rational arguments can only be true this time and will be false in another context; moreover, when there is an argument proving that $A$ is true, then there is also another argument proving that $\mathrm{A}$ is false, meaning that the rational arguments must have a solid "fulcrum" in order to form the foundation for the orientation of the individual and the community. We cannot put faith in something that is often variable. However, this does not constitute a belief in a kind of abstract metaphysics, the paranormal, religion or the like. Misak states that this kind of truth both does and does not belong to justification. Firstly, that truth is something we can possess and is not beyond the capabilities of human perception; truth is a "justified belief"14. Secondly, that belief must satisfy the following three characteristics: "goes beyond our local justification" of that belief, "stand[s] up to the rigors of inquiry", and "never lead[s] to disappointment" 15 . Misak wants to build a stable belief based on correct and recognized justifications, but she also wants that belief to overcome the variability of the justification.

However, this kind of belief (in the truth) is ultimately only a reflection of the "knowing subject" into reality. The inquirer wants to "create" a stable belief in the truth; that is, he or she wants to create his own stability in a variable

${ }^{14}$ Ibid., p.236.

15Ibid., p. 236. reality. This is in line with James' interpretation of the "Me-self" and Tran Duc Thao's analysis of the subject's reflection on objects outside himself, both of which are outlined above. This interpretation leads us to the next step in justification. Object B (Me-self) is a reflection of object A (I-self) in conversation, but only from A's perspective. From the perspective of $B, A$ is the reflection of $B$. Thus, in order for A to be connected to $B$ in the intersubjectivity, we need A to escape from his/her "Self" and his/her own reflection on B so as to truly become B. The process from $A$ reflects itself on $B$, and $A$ receives the response from $B$ as an expression of A's Self. A escaping from itself to become $B$ is the process by which the cognitive subject separates itself from the "I-self" and returns to self-awareness. Nothing else is required outside of this process.

If we argue in this direction, Rorty receives the support of his student, Robert Brandom, and his close friend, Richard Bernstein. Although Brandom is less radical than his teacher, and Bernstein is more flexible than Rorty regarding arguments that are likely to create controversies, all three philosophers acknowledge the practicality of the standards, as well as the fact that if the standards form the basis for justification and the process of creating the truth, then the daily life-experience of human beings form the basis of the standards. The three forms of expression of the standards, "conceptual, moral, and political", 16 are valid only when realized in the course of social practice.

For instance, consider the following sentence: "Everyone has the right to life". This sentence is true, and would constitute a standard of behavior among people because it satisfies all three conditions for achieving a consensus in the inter-subjectivity. Moreover, if viewed from the perspective of self-reflection, this sentence is not merely an offer to adopt an attitude of respect for the life and dignity of others, but also respect for the subject itself. This is because, when you see yourself in others and admit that others are your own reflection, you have enough reason to respect other people's lives because others are yourself; moreover, if you do not treat others the way you treat yourself, you cannot ask others to respect you as they do themselves.

In a country that still hands down the death penalty for serious murders, a murderer can certainly be sentenced to death if convicted. The question is, should that person be killed? If everyone has the right to lifethat is, no one should take the life of another, including a

${ }^{16}$ See Richard Bernstein (2010), p. 213. 
murderer-does enforcement of the death penalty against the moral standards of respect for the life and dignity of others?

All citizens in a country with a legal system must admit and follow a common code of conduct as part of the social contract that regulates behavior. This is both to ensure the existence of an individual's activity space and to avoid harm to others, even harm caused by one individual to another individual's activity space. The legalization of human behavior in society is put in place to limit conflicts and facilitate movement towards a common consensus. Therefore, when an act of infringement upon an individual's activity space takes place, punishment is issued as a reaction to the infringing act in order to avoid negative consequences such as vengeance, imitation of infringing behavior, etc. that threaten to break the stability. That is, to secure consensus and stability within a community, each individual must enter his/her "I-self" into an entity called a "contract" and accept its terms. The responses from the "Me-selfs" provide not only opportunities for reflection, but also restrictions. Any choice comes at a cost, and one's freedom is limited by the freedom of the other. When a person crosses a line, he/she must be subject to punishment. Thus, in this particular case, the sentence "Everyone has the right to life" must be reinterpreted (or re-described) as "This man, in this context, has no right to live".

As such, a standard is not a purely abstract product of thought. Instead, it is derived from justification through social practices and is adapted to the transformation of social reality. In other words, standards begin with justifications and are re-described in the justifications for the self-adjustment itself. Standards cannot stand outside the justifications. If there is a standard that surpasses the reality by which it is formed, it is merely a utopian ambition.

In other words, when we default to a statement as the "truth", we are forced to admit that it is correct, complete, unchanging, and immutable; after all, if it is variable, it cannot be the truth. However, this leads us to the next paradoxical question: if a statement is truth, it must be based on another true statement, but if we continue to trace this kind of question, a deadlock is inevitable.

\section{Does this interpretation style lead to the nihilism?}

Alan Pratt places Lyotard, Derrida and Rorty into the same group of nihilists referred to as postmodern antifoundationalists. Lyotard argues that the most striking feature of postmodern philosophers is their skepticism about the "metanarratives" that form the foundation of our cognitive processing of the world. Moreover, Derrida asserts that we cannot be sure that what we know about an object is correct or the way it really is; because we, the cognitive subject, can only join a part of the whole, all aspirations to certainty are "fictional forms". Rorty, who takes the same view, assumes that if we focus on nonverbal, immutable foundations, we will lose the ability to face and solve the variable questions of reality: "Nothing grounds our practices, nothing legitimizes them, nothing shows them to be in touch with the way things $\operatorname{are}^{\prime \prime} 17$.

Obviously, these nihilistic interpretations outlined above do not necessarily lead us to a form of doubt and negation of all our thinking abilities and the products of our thought. Osho articulates his nihilistic view by stating that when we make a concept into a noun, we kill it, in the sense that we deny its movement and growth. According to Osho, nouns do not grow and only verbs are active ${ }^{18}$. If we justify this from Rorty's point of view, when we construe a concept as the truth, we must find a justification for its correctness. This will then lead to a conflicting cycle: when there is an argument to prove something is true, there is another argument that proves the opposite.

If this perspective based on Rorty's justifications were to achieve consensus, would this lead to an overly vague and ambiguous view? How can we build sympathy and solidarity between individuals and communities on a variable and unstable foundation? Rorty answers this question by emphasizing the decisions of individuals in the conversations: that is, the meaning of each person is only valuable to the person in conversation, and we should only care about the person's response in our conversation. The objects outside our conversation are not something we need to bother with:

As I see it, the whole point of pragmatism is to insist that we human beings are answerable only to one another. We are answerable only to those who answer to us - only to conversation partners. We are not responsible to the atoms or to God, at least not until they start conversing with us ${ }^{19}$.

\footnotetext{
${ }^{17}$ From Logic to Language to Play, 1986, cited by Alan Pratt, Nihilism, https://www.iep.utm.edu/nihilism/

18 http://www.osho.com/iosho/library/read-book/online-librarymoment-jesus-crackpot-3bf89aa5$66 e ? p=d 5 d 5 e c 25245450 f e 8691 a f d 1 a e 8 b 435 d$

${ }^{19}$ See Richard Bernstein (2010), p. 212.
} 
This ambiguity articulated by Rorty has been the subject of many controversies among other philosophers with differing points of view. Bernstein calls this explanation "ethnocentric", while Jeffrey Stout named it "narcissism"20. But is this explanation truly narcissistic, given that Rorty simply wants to emphasize the role of an individual's perspective in the way he perceives and evaluates reality? "Self-reliance" 21 on the values held by an individual is not intended to prove the truth of the individual's point of view, nor to counter the differences for those values. Instead, it only narrows our consciousness into the only object that has value to it, namely the partner in conversation in a particular context. Paul Broca and Carl Wernicke's discoveries in the fields of physical and neurological surgery were summarized by Precht to suggest that our minds can only do one thing at a time; that is, we cannot focus on many different things at once, but instead can only move from one thing to another, whether quickly or slowly ${ }^{22}$. This limitation in our biological capacity (mental status) determines the limitations of our ability to cognize. Thus, the focus remains on the only object in our conversation, i.e. the object that is valuable to us, which not only improves the "I-self" in relation to the "Me-self" but also suggests new ideas for the next conversation.

Is Rorty's conception of solidarity ethnocentric, given that Rorty does not provide any evaluation of the individual or community's values based on the standard of any fixed reference system? Cheryl Misak proposes a concept that differs quite substantially from that of both Stout and Bernstein: relativity. This concept is also consistent with Rorty's suggestion of the "liberal utopian" that honors the "imagination" and "self-creation" of the cognitive subjects ${ }^{23}$. It is a kind of cultural relativism that does not impose upon the consideration of a cognitive object. The process of explaining and understanding it must come from within the culture of the object that is formed. This is similar to the theory put forward by Franz Boas and his colleagues, who propose a cultural relativism that does not deny the role of personal perspectives and the system of standards. However, to evaluate other cultures by an individual's standards, that individual must understand the values and standards of the other cultures and not be attached to the values and standards of that individual's culture ${ }^{24}$. This proposal also

\footnotetext{
20Ibid., p. 211.

21Ibid., p. 211.

${ }^{22}$ See Richard David Precht (2011), p.18-26

${ }^{23}$ See Richard Bernstein (2010), p. 211.

${ }^{24}$ In terms of methodology, Boas and his followers advocated the development of empirical approaches, which emphasized careful
}

stresses that different social contexts give rise to different values and standards. However, this does not mean that we should unconditionally accept other cultural patterns that are unbiased in their cultural context. Each evaluation is always personal. That is, each individual has the right to comment and re-describe the object according to his or her cognitive ability, data, and perspective.

\section{Conclusion}

An individual's cognitive process begins with the selfawareness of the knowing subject's reflection on others (based on the assumption of similarity of language and frame of reference), through which subjectivity is transformed into intersubjectivity. When private experience extends itself beyond the subject to a common consensus, the standards for perception and behavior are established as a guarantee of community stability. Justification acts as the nucleus of the cognitive process in which the replacement of old standards by new ones, or the reinterpretation of the foundations, is a feasible way to address a common conversation: a common conversation in which respect for individual values is an important criterion for creating tolerance and humanity. This interpretation brings a way to understand and recognize the self that cannot exist independently as a constant entity. The notion of the self exists only as an abstract projection of the subject itself perceiving in relation to the external environment. Therefore, the orientation of an individual's awareness and action cannot separate itself from the community in which it exists, i.e., the self can only be formed and reveal its features through language, and in language (in a community of language.)

\section{References}

1. Bacon M (2012) Pragmatism. An Introduction. Polity Press, Cambridge, UK.

2. Bernstein RJ (2010) The Pragmatic Turn. Polity Press, Cambridge, UK.

3. Boas F (1940) Race, Language and Culture. The University of Chicago Press, Chicago, USA.

collection of fieldwork and rejected the general, universal comparative method. At the same time, this approach emphasizes the principle of holistic analysis in understanding cultural practices. In order to explain one or more cultural customs, according to Boas, it is necessary to analyze them in three basic respects: environmental conditions, psychological factors, and related history, in which the historical factors play the most important role. See Franz Boas (1940), Race, Language and Culture. 


\section{Philosophy International Journal}

4. Brandom RB (2000) Rorty and His Critics. Blackwell Publishers Inc., Massachusetts, USA.

5. Brandom RB (2008). Between Saying and Doing. Towards an Analytic Pragmatism. Oxford University Press Inc., New York, USA.

6. Goodman RB (1995) Pragmatism - A Contemporary Reader. Routledge, New York, USA.

7. Gross N (2008) Richard Rorty - the Making of an American Philosopher. The University of Chicago Press, Chicago, USA.

8. Haack D (2006) Pragmatism Old \& New. Prometheus Books, New York, USA.

9. Hardwick CD, Donald AC (1997) Pragmatism, NeoPragmatism, and Religion. Conversations with Richard Rorty. Peter Lang Publishing, Inc., New York, USA.

10. Haworth A (1998) Free Speech. Routledge, New York, NY, USA.

11. Malachowski A (2014) Richard Rorty. Routledge, New York, USA.

12. Mendieta E (2006) Take care of freedom and truth will take care of itself. Interview with Richard Rorty. Stanford University Press, California, USA.

13. Misak C (2013) The American Pragmatists. Oxford University Press, Oxford, UK.

14. Misak C (2007) New Pragmatists. Oxford University Press, Oxford, UK.
15. Morris M(2007) An Introduction to the Philosophy of Language. Cambridge University Press, Cambridge, UK.

16. Petrucciani S (2007) La Pragmatica di un Liberale Ironico, Il Manisfesto 12 Giugno (translated in to Vietnamese by Vu Ngoc Thang).

17. Precht RD (2011) Who I am? And if so, How many? (English version, translated by Shelly Frisch). The Random House Publishing Group, New York, USA.

18. Randall EA, Lewis EH (2010) The Philosophy of Richard Rorty (volumn 32 in Library of Living Philosophers).

19. Rorty R (1979) Philosophy and the Mirror of Nature. Princeton University Press, New Jersey, USA.

20. Rorty R (1982) Consequences of Pragmatism. University of Minnesota Press, Minneapolis, USA.

21. Rorty R (1989) Contingency, Irony, and Solidarity. Cambridge University Press. Cambridge, UK.

22. Rorty R (1991) Essays on Heidegger and Others: Philosophical Papers, $2^{\text {nd }}$ (Vol). Cambridge: Cambridge University Press, UK.

23. Rorty R (2000) Philosophy and Social Hope. Penguin.

24. Rorty R (2007) Philosophy as Cultural Politics. Cambridge, UK.

25. Thao TD (1984) Investigations into the Origin of Language and Consciousness (Library of Congress Cataloging in Publication Data). Kluwer Academic Publishers, MA, USA. 